\title{
Forces of Nature on Sailing
}

Victoria Rushing ${ }^{1}$

${ }^{1}$ Affiliation not available

July 29, 2020

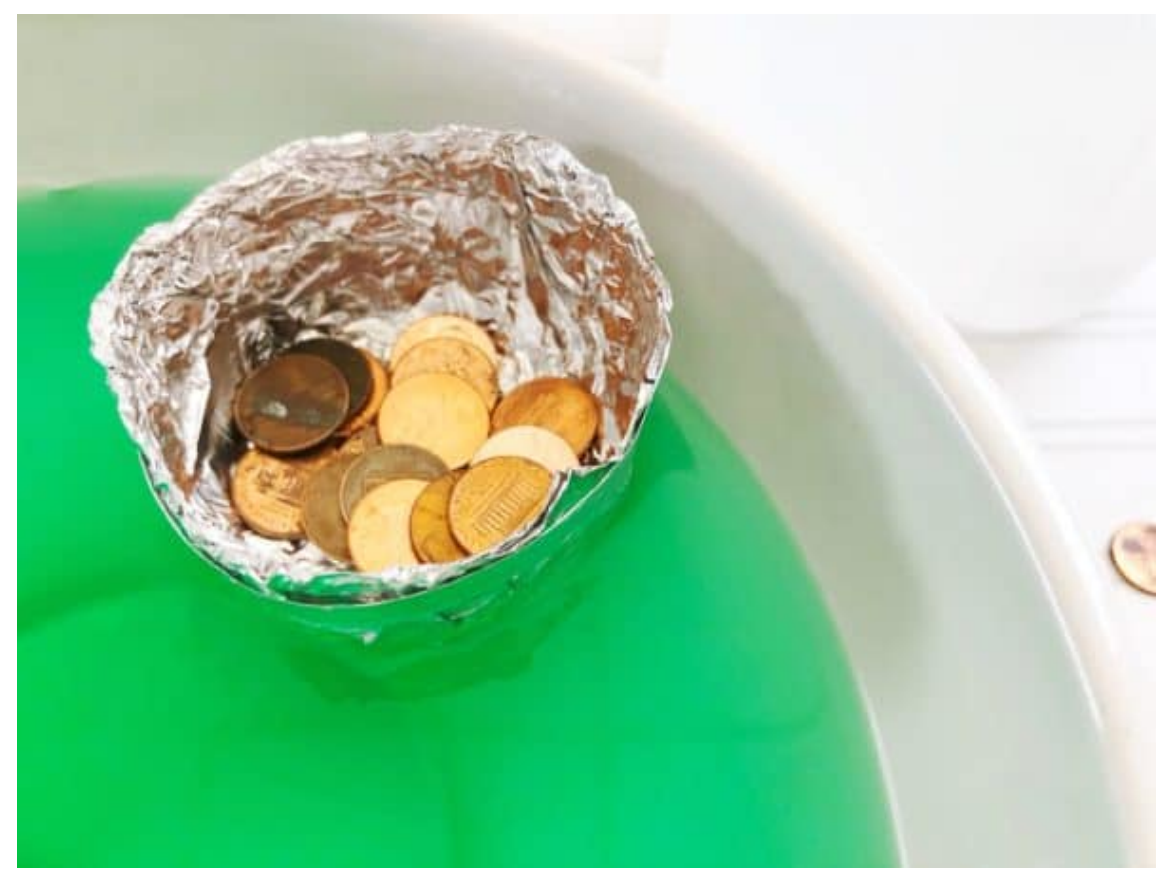

Forces of Nature in Sailing

Suggested time: 50 minutes

Overview

Students will study the effect of buoyancy and Newton's first law on the structure and mobility of sailing.

Objective 


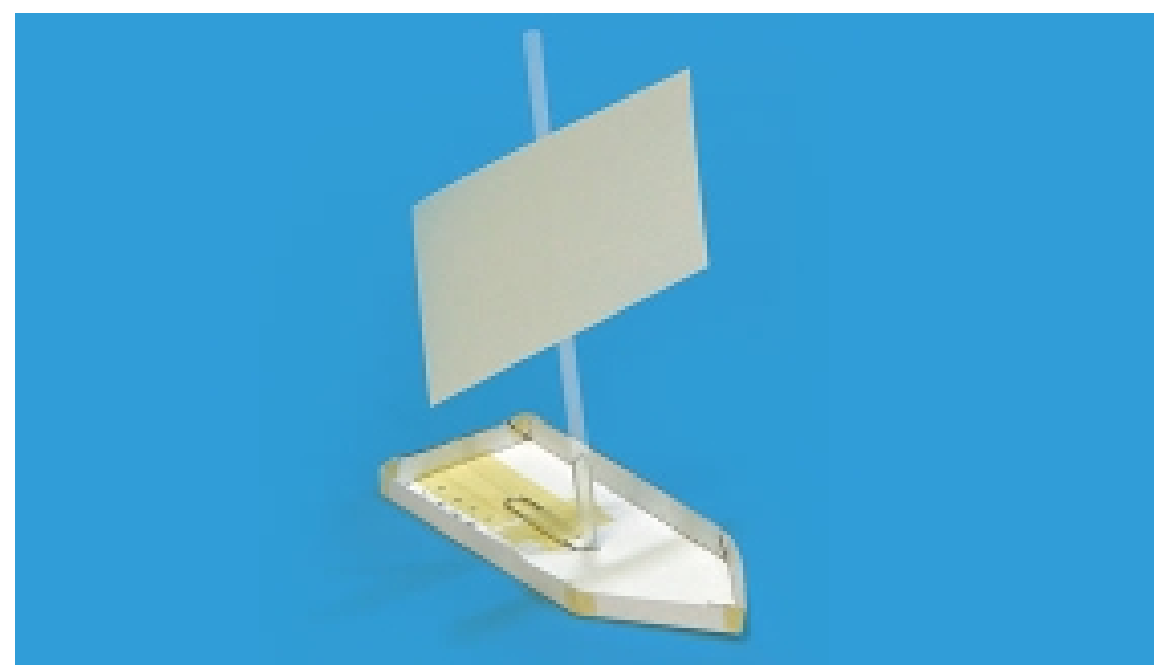

Students will design a boat body and study the effect of shape versus the load it can carry. This is looking at the force of buoyancy from the water compared to the load placed in the body of the boat. Next, they will look at sail design and see how to maximize the forward motion of the boat with different sail designs using a constant applied force to the sail.

\section{Materials}

- Aluminum foil

- 50 pennies

- Toothpicks

- Clay

- Popsicle sticks

- Corks

- Hot glue gun

- scissors

- Index cards

- Foam sheets

- Wax paper

- Colored pencils and waterproof markers

- Scotch tape

- Straw

- Calculator

- Small fan

- Small pool

- Meter stick

- stopwatch

\section{Background information}

Explain that buoyancy force is the force a liquid exerts on materials placed in it. This force opposes the weight of the object. An example of this is a beach ball in a pool. It is difficult to push the ball under the water due to the buoyancy force the water is exerting upward on the ball. This force is much greater than the force the ball in exerting downward on the water due to its mass. That is why the ball floats. When the mass of the object on the water increases to where it is exerting a force greater than the buoyancy force of the water, the object sinks. $\mathrm{F}=\mathrm{m} \times \mathrm{g}$. You can also discuss Archimedes principle: The buoyancy force exerted on a body placed in a fluid is equal to the weight of the fluid the body displaces. 
For the second part, we will prove objects move when unbalanced forces act on them. Newton's first law says objects remain at rest or remain moving until an outside force acts upon them. The boats will remain stationary until acted upon by an outside force. This principle will be used to move the boats with a sail and fan, where the fan will be the outside unbalanced force operating on the boat. We will measure how far that force moves the boat and discuss the forces that moved and stopped the motion of the boat.

\section{The Lesson}

\section{Part 1 - 30 minutes}

. This video discusses buoyancy, density, mass and Archimedes principle.

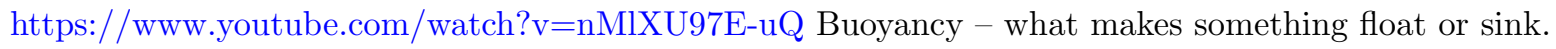

1. Watch the video on buoyancy.

2. Explain we are building a boat to hold the maximum amount of mass measured in pennies.

3. Pass out aluminum foil, popsicle sticks, clay, corks, hot glue gun and pennies.

4. Using these materials, design a boat to hold the most pennies.

5. Make sure it can float without leaking.

6. Slowly and evenly add pennies, count how many it can hold.

7. Calculate the surface area of the bottom of your boat, that touches the water.

8. Place the surface area and number of pennies your boat held in your data table.

9. Copy your classmate data into the data table.

\section{Part 2 - 15 minutes}

Explain Newton's first law that an object remains at rest until acted upon by an outside force or remains in motion till acted upon. We are going to place a sail on the boat. We will then place the boat in a pool with a fan exerting a force on it. The student will measure how far this force moves the boat.

Show the first part of this video discussing Newton's first law.

http://www.physics4kids.com/files/motion_laws.html

1. Explain the students will need to create an unbalanced force with the fan in order to push against their sails and move their boats.

2. Hand out the clay, toothpick, straw, tape, index card, scissors and colored pencils.

3. Design a sail on the index card, foam sheet or wax paper.

4. Cut it out and color.

5. Use a small blob of clay to hold the mast of the boat.

6. Tape the straw or toothpick to the index card to act as a mast.

7. Stick one end of the straw or toothpick into the clay. Tape the clay down if necessary.

8. Get the stopwatch ready and place the boat in front of the fan, in the water.

9. Time three seconds and measure how far the boat went.

10. Calculate the surface area of the sail.

11. Record on the board the surface area of the sail and how far the boat went.

\section{Data:}

\section{Part 1 - Buoyance Force vs mass}

\begin{tabular}{lll}
\hline Student Name & Surface area bottom of boat $\left(\mathrm{cm}^{2}\right)$ & Number of pennies held
\end{tabular}


Part 2 - Sail surface area vs distance moved

Name of Student

Surface area of sail $\left(\mathrm{cm}^{2}\right)$

Distance boat moved $(\mathrm{cm})$

\section{Conclusion:}

\section{Part 1.}

1. What was the surface area of your boat?

2. How many pennies did it hold?

3. Looking at the data table for the class, is there a correlation to the surface area and the number of pennies? Does more surface area hold more pennies?

4. What happened when the mass of the pennies in the boat got greater than the buoyance force of the water pushing up on the boat?

\section{Part 2}

1. Was the force of the air coming from the fan an unbalanced force?

2. What did the air from the fan cause the boat to do?

3. Did you see a correlation between the surface area of the sail and the distance the boat went? What was it?

4. What did you learn about the forces that operate on a boat to make it float and move? 